\title{
Electromyographic activity of masticatory muscles in elderly women - a pilot study
}

This article was published in the following Dove Press journal:

Clinical Interventions in Aging

II January 2017

Number of times this article has been viewed

\section{Ewelina Gaszynska' \\ Karolina Kopacz ${ }^{2}$ \\ Magdalena Fronczek- \\ Wojciechowska ${ }^{2}$ \\ Gianluca Padula ${ }^{2}$ \\ Franciszek Szatko'}

'Department of Hygiene and Health Promotion, ${ }^{2}$ Academic Laboratory of Movement and Human Physical Performance "DynamoLab", Medical University of Lodz, Lodz, Poland
Correspondence: Ewelina Gaszynska Department of Hygiene and Health Promotion, Medical University of Lodz, Hallera I, 90-647 Lodz, Poland Email ewelina.gaszynska@umed.lodz.pl
Objectives: To evaluate the effect of age and chosen factors related to aging such as dentition, muscle strength, and nutrition on masticatory muscles electromyographic activity during chewing in healthy elderly women.

Background: With longer lifespan there is a need for maintaining optimal quality of life and health in older age. Skeletal muscle strength deteriorates in older age. This deterioration is also observed within masticatory muscles.

Methods: A total of 30 women, aged 68-92 years, were included in the study: 10 individuals had natural functional dentition, 10 were missing posterior teeth in the upper and lower jaw reconstructed with removable partial dentures, and 10 were edontoulous, using complete removable dentures. Surface electromyography was performed to evaluate masticatory muscles activity. Afterwards, measurement of masseter thickness with ultrasound imaging was performed, body mass index and body cell mass index were calculated, and isometric handgrip strength was measured.

Results: Isometric maximal voluntary contraction decreased in active masseters with increasing age and in active and passive temporalis muscles with increasing age and increasing body mass index. In active masseter, mean electromyographic activity during the sequence (time from the start of chewing till the end when the test food became ready to swallow) decreased with increasing age and during the cycle (single bite time) decreased with increasing age and increasing body mass index. In active and passive temporalis muscles, mean electromyographic activity during the sequence and the cycle decreased with increasing age, increasing body mass index, and loss of natural dentition. Individuals with natural dentition had significantly higher mean muscle activity during sequence and cycle in active temporalis muscles than those wearing full dentures and higher maximal activity during cycle in individuals with active and passive temporalis muscles than in complete denture wearers.

Conclusion: Decrease in electromyographic activity of masticatory muscles in elderly women is related to age, deterioration of dental status, and body mass index.

Keywords: electromyographic activity, masseters, temporalis muscles, masticatory muscles, mastication, elderly women

\section{Background}

Age-related loss of muscle strength and function may lead to decline in physical performance. It results from the loss of muscle mass and the qualitative impairment of the muscle tissue with increasing age. ${ }^{1}$ Similar changes are observed in masticatory muscles. Palinkas et al recorded a gradual decrease in thickness of masseters at rest and maximal voluntary contraction (MVC) in a study group consisting of people aged $>60$ years. $^{2}$ Cecilio et al stated that electromyographic activity of masticatory muscles decreases in adulthood with advancing age. ${ }^{3}$ 
Raadsheer et al suggest the same general influences on the size of jaw muscles and limb muscles, but direct relationship between the strength of those muscles was not confirmed. ${ }^{4}$

The influence of an inflammatory component and nutrition is discussed in this study. Low physical performance and inflammatory states are associated with decreased hand grip strength (HGS). Additionally, significant positive correlation between HGS and body mass index (BMI) was found. ${ }^{5}$ Handheld dynamometry and bioelectrical impedance analysis provide a valid and reliable measurement of muscle strength and muscle mass, respectively. ${ }^{6}$ Missing teeth might be the measure of the past appearance of oral inflammation. ${ }^{7}$ One of the most commonly applied measurements of nutritional status is BMI. As the greater compartment of fat mass is recorded in the body composition of older individuals, more precise measurements of the metabolically active component of fat-free mass, calculated as a body cell mass index (BCMI), were applied in our study. A decrease in body cell mass in the elderly is greater than fat-free mass and appendicular skeletal muscle mass. ${ }^{8}$ Moreover, low BCMIs are observed in some pathological conditions with muscle mass depletion. ${ }^{9}$

In the present study, we want to assess to what extent those factors affect masticatory muscles and if there exists a relationship between impaired masticatory muscle function and other muscles, observed in advanced age. To keep the study more uniform, we decided to use a female population aged $>65$ years.

\section{Objectives}

To investigate the effect of age and chosen factors related to aging, such as dentition, muscle strength, and nutrition on masticatory muscles electromyographic activity during chewing in healthy elderly women.

\section{Methods Subjects}

Participants were recruited from the students of The University of the Third Age in Zgierz in 2014. The inclusion and exclusion criteria are presented in Table 1.

From 73 volunteers, 30 women, aged 68-92 years were included in the study. In the first stage 10 individuals with natural functional dentition, fulfilling inclusion criteria, were selected. In the second stage, 10 participants with missing posterior teeth in upper and lower jaws reconstructed with removable partial dentures and 10 edentulous participants using complete removable dentures, fulfilling the abovementioned criteria, as well as being similar in age to those with natural dentition, were matched.
Table I Patients inclusion and exclusion criteria in the study

\begin{tabular}{ll}
\hline Inclusion criteria & Exclusion criteria \\
\hline Age $>65$ years & Dental pathology such as active caries or \\
Female gender & Unaciodontal disease \\
Normal occlusion & Orofacial pain or having evidence of \\
(I class angle) & temporomandibular joint pathology \\
Unilateral chewing & Taking medications that affect muscle function \\
pattern & such as myorelaxants (eg, Baclofen, Tizanidine, \\
& and Tolperisone) and psychotropic drugs \\
& Diabetes mellitus \\
& Musculoskeletal dysfunction \\
& Stroke \\
& Parkinson's disease \\
& Depression \\
\hline
\end{tabular}

The study was approved by the Ethics Committee at the Medical University of Lodz, Poland, decision number RNN/181/13/KB. All participants provided their written informed consent to participate in the study.

\section{Protocol}

\section{Surface electromyography}

To start each trial, the test food was placed on the tongue by the examiner. The subject then closed the teeth into occlusion keeping the test food between the tongue and started unilateral chewing when the signal was given. The test food was chewed until the participant decided it was ready to swallow. This phase is one sequence. Participants were asked not to move their heads during the recordings, controlled by three observers. Two 15-minute sessions were held for each individual. The first session was held to familiarize subjects with the experimental protocol. Only data from the second session were analyzed. During each session, the participant chewed three samples of test food (blanched California almond). Blanched almond in standard one size $(23 \times 11 \mathrm{~mm})$ was chosen as the test food for the study because it has a convenient size and texture, as well as being natural and better accepted by participants than Optosil tablets.

The skin over the left and right masseter and anterior temporalis muscles was shaved and cleaned with alcohol. The electromyography sensors were placed on the skin with the use of pediatric electrocardiogram round $\mathrm{Ag} / \mathrm{AgCl}$ pre-gelled surface electrodes of $30 \mathrm{~mm}$ diameter. Electrodes placement was consistent with SENIAM recommendations. ${ }^{10}$ Muscle activity was evaluated with BTS FREEEMG300 (BTS Bioengineering, Milan, Italy) and data were subsequently processed with the SMART analyzer version 1.10.0225 using a 20-Hz high-pass Butterworth filter, 450-Hz lowpass Butterworth filter, full-wave rectification, and root 
mean square with a time window of 300 milliseconds. The patients were examined three times: during rest - without chewing, during isometric MVC, and during chewing. Prior to the test, resting values were collected for a period of 10 seconds. Single isometric MVC was examined over a period of 20 seconds. The maximum peak during MVC was calculated. The seating position was standardized. The chewing movement was tested three times (three sequences were recorded).

The following parameters were calculated for each masseter and pterygoid muscle: mean, minimum, maximum muscle activity at rest; muscle activity during isometric MVC; mean muscle activity in relation to MVC; chewing sequence time (time from the start of chewing till the end when the test food became ready to swallow); cycle time (single bite time); the number of bites during chewing sequence; mean, minimum, maximum muscle activity during single bite; and mean, minimum, maximum muscle activity during chewing sequence.

\section{The difference between masseter muscle thickness at rest and MVC (DMMT)}

Measurements of masseter muscles thickness at rest and in MVC with ultrasound imaging were performed unilaterally at the active side (preferred for chewing). The subject sat in an armchair without head support, so the Frankfurt surface was parallel to the ground and the 6-MHz linear-array transducer was placed perpendicular to the mandible ramus over the thickest part of the masseter, previously found by palpation, using a real-time ultrasound scanner (Micromaxx SonoSite Inc., Bothell, WA, USA). The difference between masseter muscle thickness at rest and MVC was calculated and analyzed.

\section{BMI}

BMI was calculated using body mass in kilograms divided by the square of body height in meters. Height was calculated using demi-span measurement protocol. ${ }^{11}$
BCMI

With Bodycomp MF Plus Akern, according to the manufacturer's guidelines, body impedance was measured. Electrodes were placed on a single foot and hand on the same side of the patient who was in a relaxed supine position. The device operated in frequencies ranging from 5 to $50-100 \mathrm{kHz}$.

In order to calculate BMI and BCMI, impedance values, height, and body mass were introduced into Bodygram MF Plus v. 1.2 for Windows program.

\section{HGS}

HGS was measured with a handheld dynamometer (DynEx I, Akern SRL; MD Systems Inc., Westerville, OH, USA) in subjects sitting with a bent upper extremity at $90^{\circ}$. Mean values of two consecutive measurements of dominant HGS were recorded.

\section{Statistical analysis}

Using STATISTICA version 10.0 software, analyses were performed to assess the association between masticatory muscles electromyographic activity and the following factors: age, dentition, BMI, BCMI, HGS, and DMMT.

Multivariate models were constructed with forward variable selection with Akaike's criterion. The following models were tested with one explanatory variable, and from these models one with the lowest values of the Akaike's criterion was chosen. Next, using the previously chosen model with one of the explanatory variables another variable was added. The procedure added the following variable to the model, until the moment the following variables did not diminish the Akaike's criterion. In the model the remaining respective variables with a $P$-value from Student's $t$-test of $>0.05$ were added, providing that their presence improve the model.

\section{Results}

Demographic data and mean values of studied parameters are presented in Table 2. There were no statistically significant differences in BMI between dental categories groups. Six

Table 2 Studied parameters in relation to dental status categories

\begin{tabular}{|c|c|c|c|}
\hline Variable & $\begin{array}{l}\text { Complete removable } \\
\text { dentures wearers }\end{array}$ & $\begin{array}{l}\text { Partial removable } \\
\text { dentures wearers }\end{array}$ & $\begin{array}{l}\text { Individuals with } \\
\text { natural dentition }\end{array}$ \\
\hline Age (years), mean $\pm S D$ & $84.40 \pm 6.08$ & $80.11 \pm 9.10$ & $79.78 \pm 7.63$ \\
\hline Hand grip strength $(\mathrm{kg})$, mean $\pm \mathrm{SD}$ & $13.65 \pm 3.87$ & $13.18 \pm 5.05$ & $\mid 4.84 \pm 4.79$ \\
\hline Body mass index $\left(\mathrm{kg} / \mathrm{m}^{2}\right)$, mean $\pm \mathrm{SD}$ & $24.69 \pm 4.03$ & $27.85 \pm 3.89$ & $28.67 \pm 4.20$ \\
\hline Body cell mass index $\left(\mathrm{kg} / \mathrm{m}^{2}\right)$, mean $\pm \mathrm{SD}$ & $6.09 \pm 0.83$ & $6.33 \pm 0.86$ & $6.50 \pm 1.18$ \\
\hline $\begin{array}{l}\text { Difference of masseter muscle tension } \\
(\mathrm{mm}), \text { mean } \pm S D\end{array}$ & $3.70 \pm 1.70$ & $3.67 \pm 2.18$ & $3.67 \pm 1.73$ \\
\hline
\end{tabular}

Abbreviation: SD, standard deviation. 
Table 3 Maximal voluntary contraction in masseters and temporalis muscles in relation to descriptive variables: multivariate models with Akaike's criterion of variables selection

\begin{tabular}{llll}
\hline Variable & \multicolumn{3}{l}{ Maximal voluntary contraction } \\
\cline { 2 - 4 } & $\begin{array}{l}\text { Active } \\
\text { masseter }\end{array}$ & $\begin{array}{l}\text { Active } \\
\text { temporalis } \\
\text { muscle }\end{array}$ & $\begin{array}{l}\text { Passive } \\
\text { temporalis } \\
\text { muscle }\end{array}$ \\
\hline Age & $-2.50 \mathrm{I}, P=0.054$ & $-4.055, P=0.00 \mathrm{I}$ & $-3.589, P=0.002$ \\
Body mass index & & $-3.368, P=0.120$ & $-3.897, P=0.057$ \\
\hline
\end{tabular}

Notes: Data are presented as coefficient and $P$-value. Variables that have not been included in the model are omitted. The level of significance was set at 0.05 . In the model variables with a $P$-value from Student's $t$-test of $>0.05$ were also added, providing that their presence improve the model.

subjects were classified as obese class I $\left(\geq 30.00-<35 \mathrm{~kg} \mathrm{~m}^{2}\right)$, 9 were overweight ( $\geq 25-<30 \mathrm{~kg} / \mathrm{m}^{2}$ ), and 15 were of normal range $\left(\geq 18.50-<25 \mathrm{~kg} / \mathrm{m}^{2}\right)$ according to the classification of BMI by the World Health Organization. ${ }^{12}$

Mean DMMT decreases with age. Each year it diminishes by $0.089 \mathrm{~mm}(P=0.049)$. There were no statistically significant differences in DMMT between dental categories groups (Table 2).

MVC decreased in the active masseter with increasing age and in active and passive temporalis muscles with increasing age and increasing BMI (Table 3).

\section{Mean muscle activity $(\mu \mathrm{V})$}

Mean electromyographic activity during the sequence decreased in the active masseter with increasing age and in active and passive temporalis muscles with increasing age, increasing BMI, and loss of natural dentition (Table 4).

Similarly, mean electromyographic activity during the cycle decreased in the active masseter with increasing age and increasing BMI and in active and passive temporalis muscles with increasing age, increasing BMI, and loss of natural dentition (Table 4).

\section{Maximal muscle activity $(\mu \mathrm{V})$}

Maximal electromyographic activity during the sequence decreased in the active temporalis muscle with increasing age, increasing BMI, and loss of natural dentition and also at the same time, decreased in passive temporalis muscle with increasing age and decreasing BCMI (Table 5).

Maximal electromyographic activity during the cycle decreased in the active masseter with loss of natural dentition and at the same time, decreased in active and passive temporalis muscles with increasing age, increasing BMI, and loss of natural dentition (Table 5).

Individuals with natural dentition had significantly higher mean muscle activity during sequence and cycle in active temporalis muscles $(50.856 \pm 23.746$ and $51.752 \pm 24.113)$ than those wearing full dentures $(25.164 \pm 13.001$ and $25.844 \pm 13.291$ ) and higher maximal activity during cycle in individuals with active and passive temporalis muscles $(77.701 \pm 34.246$ and $59.803 \pm 48.997)$ than in complete denture wearers (33.862 \pm 19.411 and 29.392 \pm 13.948$)$.

Statistically significant associations were not found between mean muscle activity in the sequence (\%MVC), sequence time, single bite time, mean number of bites in the sequence nor the following descriptive variables: age, dentition, DMMT, BMI, BCMI, and HGS.

\section{Discussion}

Surface electromyography is a good objective method of masticatory muscles activity evaluation. ${ }^{13}$ Masticatory performance (food break down in a bolus ready to swallow) is not correlated with muscle effort, but is correlated with MVC. ${ }^{14}$ However, numerous studies have shown that direct influence of age on masticatory performance is limited, but electromyographic activity decreased with advanced age. . $^{2,3,15,16}$ In our study, we observed MVC and mean activity during the

Table 4 Mean muscle activity during chewing in masseters and temporalis muscles in relation to descriptive variables: multivariate models with Akaike's criterion of variables selection

\begin{tabular}{|c|c|c|c|c|c|c|}
\hline \multirow[t]{2}{*}{ Variable } & \multicolumn{3}{|c|}{ Mean muscle activity during sequence } & \multicolumn{3}{|c|}{ Mean muscle activity during cycle } \\
\hline & $\begin{array}{l}\text { Active } \\
\text { masseter }\end{array}$ & $\begin{array}{l}\text { Active } \\
\text { temporalis muscle }\end{array}$ & $\begin{array}{l}\text { Passive } \\
\text { temporalis muscle }\end{array}$ & $\begin{array}{l}\text { Active } \\
\text { masseter }\end{array}$ & $\begin{array}{l}\text { Active } \\
\text { temporalis muscle }\end{array}$ & $\begin{array}{l}\text { Passive } \\
\text { temporalis muscle }\end{array}$ \\
\hline Age & $-0.8|2, P=0.1| I \mid$ & $-1.600, P=0.017$ & $-0.924, P=0.070$ & $-1.184, P=0.045$ & $-1.677, P=0.002$ & $-0.986, P=0.060$ \\
\hline Body mass index & & $-2.693, P=0.023$ & $-2.064, P=0.027$ & $-|.49|, P=0.17 \mid$ & $-2.8|3, P=0.02|$ & $-2.160, P=0.023$ \\
\hline $\begin{array}{l}\text { Complete } \\
\text { removable denture }\end{array}$ & & Reference & Reference & & Reference & Reference \\
\hline $\begin{array}{l}\text { Partial removable } \\
\text { denture }\end{array}$ & & $15.995, P=0.146$ & $14.799, P=0.09 \mid$ & & $15.430, P=0.169$ & $14.910, P=0.095$ \\
\hline Natural dentition & & $25.692, P=0.044$ & $18.386, P=0.065$ & & $25.908, P=0.047$ & $18.204, P=0.073$ \\
\hline
\end{tabular}

Notes: Data are presented as coefficient and $P$-value. Variables that have not been included in the model are omitted. The level of significance was set at 0.05 . In the model variables with a $P$-value from Student's $t$-test of $>0.05$ were also added, providing that their presence improve the model. 
Table 5 Maximal muscle activity during chewing in masseters and temporalis muscles in relation to descriptive variables: multivariate models with Akaike's criterion of variables selection

\begin{tabular}{|c|c|c|c|c|c|}
\hline \multirow[t]{2}{*}{ Variable } & \multicolumn{2}{|c|}{ Maximal muscles activity during sequence } & \multicolumn{3}{|c|}{ Maximal muscles activity during cycle } \\
\hline & $\begin{array}{l}\text { Active } \\
\text { temporalis muscle }\end{array}$ & $\begin{array}{l}\text { Passive } \\
\text { temporalis muscle }\end{array}$ & $\begin{array}{l}\text { Active } \\
\text { masseter }\end{array}$ & $\begin{array}{l}\text { Active } \\
\text { temporalis muscle }\end{array}$ & $\begin{array}{l}\text { Passive } \\
\text { temporalis muscle }\end{array}$ \\
\hline Age & $-3.849, P=0.017$ & $-2.305, P=0.083$ & & $-2.256, P=0.034$ & $-1.338, P=0.084$ \\
\hline Body mass index & $-6.912, P=0.017$ & & & $-4.199, P=0.027$ & $-3.533, P=0.014$ \\
\hline Body cell mass index & & $21.858, P=0.067$ & & & \\
\hline Complete removable denture & Reference & Reference & Reference & Reference & Reference \\
\hline Partial removable denture & 42.027, $P=0.115$ & & $3.389, P=0.823$ & $23.329, P=0.187$ & $21.295, P=0.109$ \\
\hline Natural dentition & $59.177, P=0.054$ & & $26.935, P=0.086$ & $43.839, P=0.034$ & $30.41 \mathrm{I}, P=0.047$ \\
\hline
\end{tabular}

Notes: Data are presented as coefficient and $P$-value. Variables that have not been included in the model are omitted. The level of significance was set at 0.05 . In the model variables with a $P$-value from Student's $t$-test of $>0.05$ were also added, providing that their presence improve the model.

chewing sequence and single bite, decrease with advanced age. This suggests masticatory performance deterioration with increased age of the studied elderly women, also in those with natural dentition.

With advanced age, muscle mass and muscle mechanical performance are impaired. ${ }^{17}$ Additionally, diminishing of cross-sectional area of masseters and medial pterygoids with age has been reported. ${ }^{18}$ We also noticed a gradual decrease in masseter muscle thickness at rest and MVC with increasing age. Muscle cross-sectional area is more strongly affected by age and sex than diabetes. ${ }^{9}$ Moreover, with decreasing cross-sectional area of the masseters a maximum bite force decreases. ${ }^{15}$ There were no statistically significant DMMT differences between dental categories groups; in complete removable denture wearers, we observed lower muscle activity during chewing than in individuals with functional natural dentition.

However, the effect of post-canine tooth units and bite force on masticatory performance is significant (masticatory performance is worse in subjects wearing complete or partial removable dentures); individuals with missing teeth and impaired masticatory function do not chew longer than individuals with no missing teeth. This suggests compensation by swallowing larger particles of food or avoiding difficult-to-chew foods. ${ }^{15}$ This statement is in agreement with our results. The number of cycles and duration of sequence did not change with increasing age. ${ }^{13}$

Besides age and compromised dentition, masticatory muscles activity in elderly women is related to their nutritional status. Our results suggest that having BMI in normal range can be associated with higher muscle activity during chewing. In our study, BCMI did not appear to be as important a factor as BMI concerning masticatory muscle activity. Body cell mass measurement with electrical bioimpedance has been used by other authors to assess skeletal muscle function, and this has shown that low body cell mass is associated with poor nutrition, low muscle strength, and reduced functional performance. ${ }^{19} \mathrm{~A}$ relationship between masticatory function, dietary selection, and nutritional intake is essential for maintaining musculoskeletal function..$^{20} \mathrm{~A}$ positive relationship has been shown to occur between body cell mass and HGS. ${ }^{21,22}$ Moreover, HGS was found to be significantly correlated with the strength and power of the muscles of the lower limbs, the cross-sectional size of the Achilles tendon, and knee bending torque. ${ }^{23}$ Hämäläinen et al observed a correlation between HGS and the number of teeth present in a group of elderly men, but they did not find an association between the number of teeth and change in HGS over the course of 5 years of follow-up. ${ }^{7} \mathrm{We}$ have not found association between masticatory muscles activity and HGS, although in our previously conducted study, HGS was positively correlated with strong masseter muscle tension. ${ }^{24}$

\section{Conclusion}

Decrease in electromyographic activity of masticatory muscles in elderly women is related to age, deterioration of dental status, and body mass index. Age and dental status influence masticatory muscle activity mainly at the active chewing side.

Further study is needed to verify our preliminary results as to whether being obese or overweight is associated with lower temporalis muscles activity during chewing.

\section{Acknowledgment}

The study was funded by Medical University of Lodz grant number 502-03/6-024-01/502-64-073.

\section{Disclosure}

The authors report no conflicts of interest in this work. 


\section{References}

1. Legrand D, Adriaensen W, Vaes B, Matheï C, Wallemacq P, Degryse J. The relationship between grip strength and muscle mass (MM) inflammatory biomarkers and physical performance in community-dwelling very old persons. Arch Gerontol Geriatr. 2013;57(3):345-351.

2. Palinkas M, Nassar MS, Cecilio FA, et al. Age and gender influence on maximal bite force and masticatory muscles thickness. Arch Oral Biol. 2010;55(10):797-802.

3. Cecilio FA, Regalo SC, Palinkas M, et al. Ageing and surface EMG activity patterns of masticatory muscles. J Oral Rehabil. 2010;37(4): 248-255.

4. Raadsheer MC, Van Eijden TM, Van Ginkel FC, Prahl-Andersen B. Human jaw muscle strength and size in relation to limb muscle strength and size. Eur J Oral Sci. 2004;112(5):398-405.

5. Kaur M. Age-related changes in hand grip strength among rural and urban Haryanvi Jat females. HOMO-J Comp Hum Biol. 2009;60(5):441-450.

6. Mijnarends DM, Meijers JMM, Halfens RJG, et al. Validity and reliability of tools to measure muscle mass, strength, and physical performance in community-dwelling older people: a systematic review. $J$ Am Med Dir Assoc. 2013;14(3):170-178.

7. Hämäläinen $P$, Rantanen $T$, Keskinen $M$, Meurman JH. Oral health status and change in handgrip strength over a 5 -year period in 80 -yearold people. Gerodontology. 2004;21(3):155-160.

8. Kyle UG, Genton L, Hans D, Karsegard L, Slosman DO, Pichard C. Agerelated differences in fat-free mass, skeletal muscle, body cell mass and fat mass between 18 and 94 year. Eur J Clin Nutr. 2001;55(8):663-672.

9. Talluri A, Liedtke R, Mohamed EI, Maiolo C, Martinoli R, De Lorenzo A. The application of body cell mass index for studying muscle mass index for studying muscle mass changes in health and disease conditions. Acta Diabetol. 2003;40(Suppl 1):S286-S289.

10. The SENIAM project [homepage on the Internet]. SENIAM 8. European Recommendations for Surface ElectroMyoGraphy. Available from: http://www.seniam.org/. Accessed November 30, 2016.

11. Bassey EJ. Demi-span as a measure of skeletal size. Ann Hum Biol. 1986; 13(5):499-502.

12. World Health Organization. Physical status: the use and interpretation of anthropometry-report of WHO Expert Committee, technical report series No. 854. Geneva: World Health Organization; 1995. Available from: http://apps.who.int/iris/bitstream/10665/37003/1/ WHO_TRS_854.pdf. Accessed December, 2015.
13. Peyron MA, Blanc O, Lund JP, Woda A. Influance of age on adaptability of human mastication. J Neurophysiol. 2004;92(2):773-779.

14. Paphangkorakit J, Chaiyapanya N, Sriladlao P, Pimsupa S. Determinants of chewing efficiency using muscle work. Arch Oral Biol. 2008;53(6): 533-537.

15. Hatch JP, Shinkai RSA, Sakai S, Rugh JD, Paunovich ED. Determinants of masticatory performance in dentate adults. Arch Oral Biol. 2001; 46(7):641-648.

16. Feldman RS, Kapur KK, Alman JE, Chauncey HH. Aging and mastication: changes in performance and in the swallowing threshold with natural dentition. J Am Geriatric Soc. 1980;28:97-103.

17. Porter MM, Vandervoort AA, Lexell J. Aging of human muscle: structure, function, and adaptability. Scand J Med Sci Sports. 1995; 5(3):129-142.

18. Newton JP, Abel RW, Robertson EM, Yemm R. Changes in human masseter and medial pterygoid muscles with age: a study by computed tomography. Gerodontics. 1987;3(4):151-154.

19. Guigoz Y, Lauque S, Vellas BJ. Identifying the elderly at risk for malnutrition. The mini nutritional assessement. Clin Geriatr Med. 2002; 18(4):737-757.

20. Pirlich M, Schutz T, Spachos T, et al. Bioelectrical impedance analysis is a useful bedside technique to assess malnutrition in cirrhotic patients with and without ascities. Hepatology. 2000;32(6):1208-1215.

21. Salvi F, Miller MD, Grilli A, et al. A manual of guidelines to score the modified cumulative illness rating scale and its validation in acute hospitalized elderly patients. J Am Geriatr Soc. 2008;56(10):1926-1931.

22. Flynn MA, Nolph GB, Baker AS, Martin WM, Krause G. Total body potassium in aging humans: a longitudinal study. Am J Clin Nutr. 1989;50(4): 713-717.

23. Ritchie CS, Joshipura K, Hung HC, Douglass CW. Nutrition as a mediator in the relation between oral and systemic disease: association between specific measures of adult oral health and nutrition outcomes. Crit Rev Oral Biol Med. 2002;13(3):291-300.

24. Gaszynska E, Godala M, Szatko F, Gaszynski T. Masseter muscle tension, chewing ability, and selected parameters of physical fitness in elderly care home residents in Lodz, Poland. Clin Interv Aging. 2014;9: $1197-1203$.
Clinical Interventions in Aging

\section{Publish your work in this journal}

Clinical Interventions in Aging is an international, peer-reviewed journal focusing on evidence-based reports on the value or lack thereof of treatments intended to prevent or delay the onset of maladaptive correlates of aging in human beings. This journal is indexed on PubMed Central, MedLine,

\section{Dovepress}

CAS, Scopus and the Elsevier Bibliographic databases. The manuscript management system is completely online and includes a very quick and fair peer-review system, which is all easy to use. Visit http://www.dovepress. com/testimonials.php to read real quotes from published authors. 